\title{
Modeling and Optimization of Diesel-LPG Dual Fuel Engine's Performance: An ANN Approach
}

\author{
J. P. Yadav ${ }^{1}$, Amit Kumar ${ }^{2 *}$ and Ravi Kant ${ }^{3}$ \\ ${ }^{1,2,3} \operatorname{Dr} B$ R A College of Agril Engg \& Tech, Etawah - 206001 (UP), India \\ ${ }^{1}$ jpyadav_caet@yahoo.com, ${ }^{2 *}$ amit.jnv188@gmail.com, ${ }^{3}$ ravikantsai95@gmail.com
}

\begin{abstract}
The crises of natural resources as one fossil fuel are alarming worldwide due to depleting reserves compelling technocrats, scientists, researchers, manufacturers and the stakeholders to go for researches, experiments, and trials with all possible options from all probable aspects using hybrid technology to dual triple fuel such as solid, liquid or gaseous fuel or its combinations to emerge alternatives supplementing the sustainably required need of fossil fuel for robust, cost effective, clean and green technology. In this paper one of the analyses using Artificial Neural Network (ANN) is applied on a retrofitted experimental setup using diesel as primary and LPG as secondary fuel optimizing the thermodynamic parameters to obtain maximum work output at higher thermal efficiency. The ANN is trained with the experimental data to stimulate the results for the network which gives least Mean Square Error (MSE) and lowest Mean Absolute Percentage Error (MAPE) being a function to optimize the results. The optimization is done with the help of GENETIC ALGORITHM to minimize the negativity of function to get maximized results.
\end{abstract}

Keywords: Diesel-LPG as duel fuel, Artificial Neural Network, Genetic algorithm

\section{Introduction}

With greater exploitation of fossil fuel reserves the growing industrialization is a threat to the developing countries and to the future generation of its effects visibly witnessed in the form of global warming, climate change, melting of glaciers causing a great risk to the survivability of all living beings. The lives at cosmopolitan and metropolitan cities are hell with polluted environments around them. The technocrats, scientists, researchers and manufacturers are concentrating to find out alternatives of conventional petroleum fuels due to its depleting base and adverse impact on ecosystem of the globe. Excessive use of fossil fuels have already disturbed the ecosystem and even nature is unable to establish the balance between the system and surroundings and the effect in the form of global warming, climate change, unpredictable behavior weather are visibly seen. The sustainable use of fossil fuel with improved method of combustion using hybrid technology with change in the design configuration of existing engines are of prime concerns. With greater awareness about the effective use alternative fuels/ mixed fuels and dual fuels with some retrofitting on the existing design can mitigate to some extent the risk of extreme polluting atmosphere and save conventional fuels in a environment friendly way. Thus the use of LPG with diesel in compressed ignition engine is one of the solutions of this problem. LPG is one of the alternative gaseous fuel well known by the name 'AUTO GAS' refined from the product of petroleum primarily consists of propane, propylene, butane and other high hydrocarbon. LPG has high calorific value because of high octane. Its high octane number make it suitable for spark ignition engine and lower cetane number make it difficult to be used in large proportion in compression ignition

* Corresponding Author 
engine due to high cyclic variation, hence LPG could be a viable options to use with $\mathrm{CI}$ engine in dual fuel mode [1].

In the work by K. Mohan Kumar, Dr. D. Azad [2] noted that use of generator is becoming essential on the places where the power supply through the grid is not possible or not provided till date or when grid fails, there the dual fuel engine because of its high performance and low emission gets a place. LPG is used in vehicles with gasoline and diesel but its use in the diesel power plant as dual fuel at higher loads are considered by keeping environmental issues into consideration. The engine is tested for its performance along with emissions analysis at different proportions of Diesel and LPG including 100\% diesel. In the experimental setup with simple modification they supplied LPG with air into the engine.

Similarly, in the work by Bilcan, A., Le C orre, O., Tazerout, M., Ramesh [3] it is found dual fuel engines have the possibility to use wide variety of gaseous fuel efficiently with lesser emission of smoke and particulate than their diesel counterparts. These engines use primarily gaseous fuels like biogas, producer gas and LPG; etc and supplement the major share of the input energy. They characterize the combustion process in a dual fuel engine to develop a model. The complete combustion process is divided into three stages as the premixed combustion of diesel fuel, the combustion for premixed gaseous fuel and the diffusion combustion. A fairly good agreement was observed between the simulation and the experimental results with an error lesser than $2 \%$.

Deo Raj Tiwari, Gopal P. Sinha [4] present observations, results and analysis with respect to the experiments conducted on fuel mix used in a setup on CI engine. LPG mixed with air at different concentrations is injected through the engine intake manifold while the diesel is injected through mechanical injection equipment at the end of compression stroke to obtain the experimental data at different loads. The analysis of power output and the impact on thermal efficiency to control emission parameters are done.

Adarsh Rai, N. Satheesh Kumar, Srinivasa Pai P, and B.R. Shrinivasa Rao [5] have used fuzzy logic to model the performance and emission parameters in Liquid Petroleum Gas (LPG)-diesel dual fuel engine. Considered performance parameters were brake specific energy consumption (BSEC) and brake thermal efficiency (BTE) and for emission, parameters considered are exhaust gas temperature (EGT) and smoke. Adaptive neuro fuzzy inference system (ANFIS), a hybrid technique involving fuzzy logic and artificial neural network (ANN) have been used to develop a model and its performance was compared by traditional fuzzy logic based model. It was found that ANFIS out performed conventional fuzzy logic model based on $\mathrm{R}^{2}$ value and prediction accuracy on test data.

Here in this paper Artificial Neural Network used for modeling and further genetic algorithm is used for the optimization of the ANN.

\section{Experimental Setup, Fabrication and Working}

The experimental setup is shown in the Figures $1 \mathrm{a} \& 1 \mathrm{~b}$ in which LPG is mixed in air at intake manifold which is divided into two parts, one of which is connected to the LPG cylinder while other part is free for the intake of air. A load testing panel is connected to the alternator of the generator to vary the load conditions. An exhaust gas temperature sensor is connected at the exhaust of the engine which measures the temperature of the exhaust gases. A flow meter is used between the cylinder and intake manifold to measure the flow rate of LPG. A burette is used to measure the amount of fuel consumed during the experiment. 


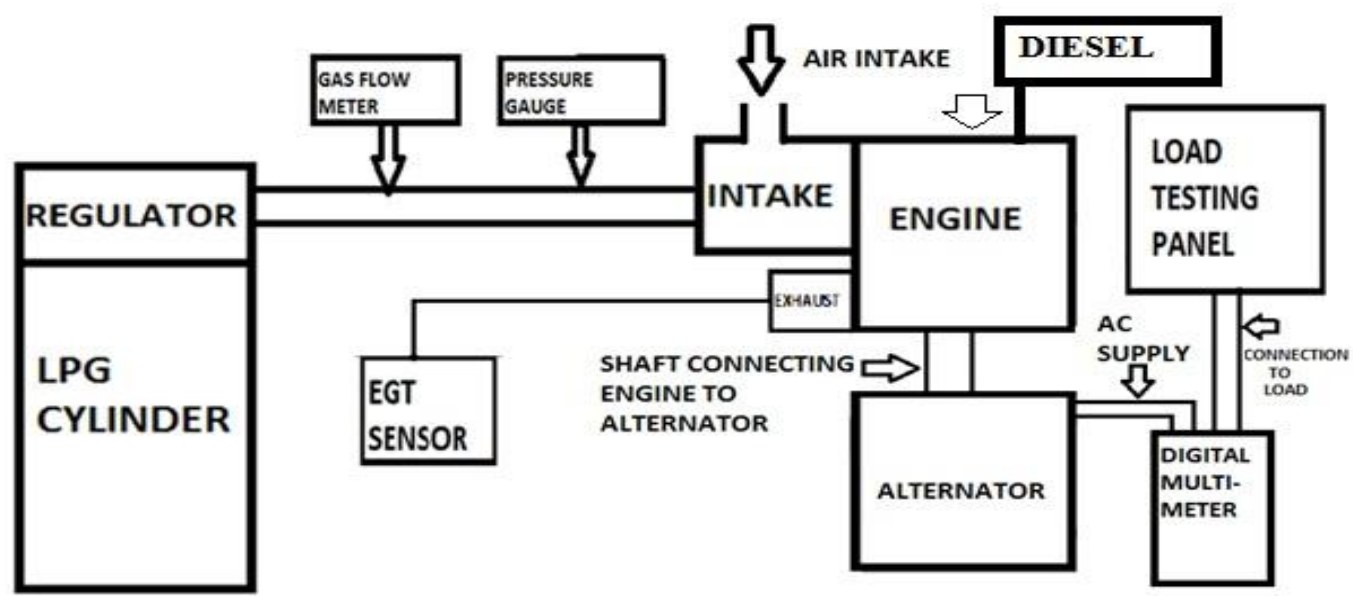

Figure 1a. Experimental Setup

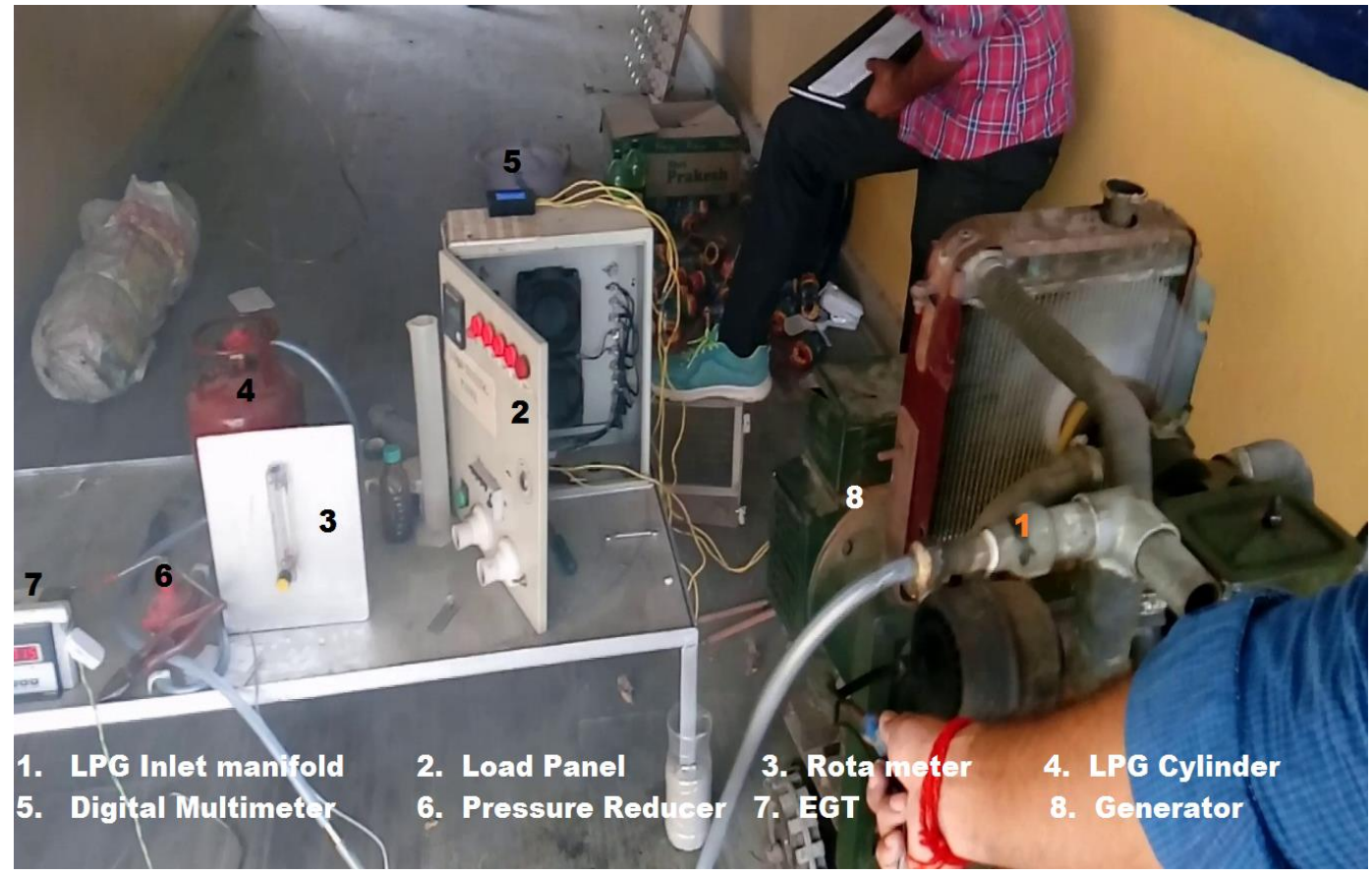

Figure 1b. Experimental Setup used for taking Readings

The readings of measurable parameters like LPG flow rate (lpm), maximum throat opening (\%) and load (\%), voltage developed (volts), electrical power developed (W), exhaust gas temperature $\left({ }^{\circ} \mathrm{C}\right)$ and fuel consumption $(\mathrm{ml} / \mathrm{s})$ are taken from the dual fuel engine setup for every 3 minutes of running to calculate the brake thermal efficiency, brake specific fuel consumption $(\mathrm{Kg} / \mathrm{KWh})$ and brake specific energy consumption $(\mathrm{MJ} / \mathrm{kWh})$.

In this paper with the use of ANN in MATLAB for modeling and optimization of the results has been carried out using the combination of input parameters in the experimental setup in an iterative manner at certain intervals to explore the possibilities of a set of optimized input parameters which could maximize the output and it is found out the maximum electrical power developed is 3638 watts for $1 \mathrm{lpm}$ of LPG at 95\% maximum throat opening and $70 \%$ load. 


\subsection{ANN Modeling}

An artificial neural network is created in neural network toolbox (nntool) in MATLAB for the modeling of dual fuel engine. Several models were designed and tested within order to determine the optimal architecture, the most suitable activation function and the best training algorithm. The main selection criteria used were mean absolute percentage error (MAPE) in prediction and the regression coefficient $R$ values of the trained models.

The network type selected for each of the three ANN was fed forward back propagation with single hidden layer. Back propagation minimized the total mean square error of the output computed by the network using gradient decent method. The training function used was TRAINLM and adaptive learning function was LEARNGDM. The transfer function used for both hidden and output layer was TANSIG. The numbers of neurons in the hidden layer were selected based on mean absolute percentage error (MAPE) values so ANN model with 12-neuron in hidden layer were selected. Also the regression coefficient $\mathrm{R}$ values were close to 1 indicating there is a strong correlation between the targeted outputs and network outputs. The developed models are shown schematically in Figure 2.

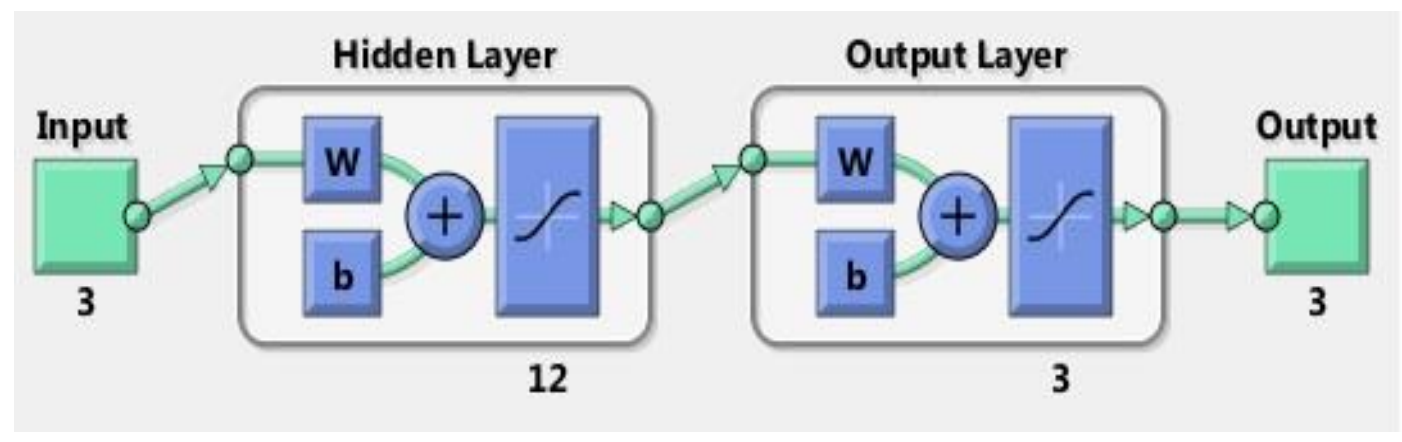

Figure 2. Artificial Neural Network (ANN)

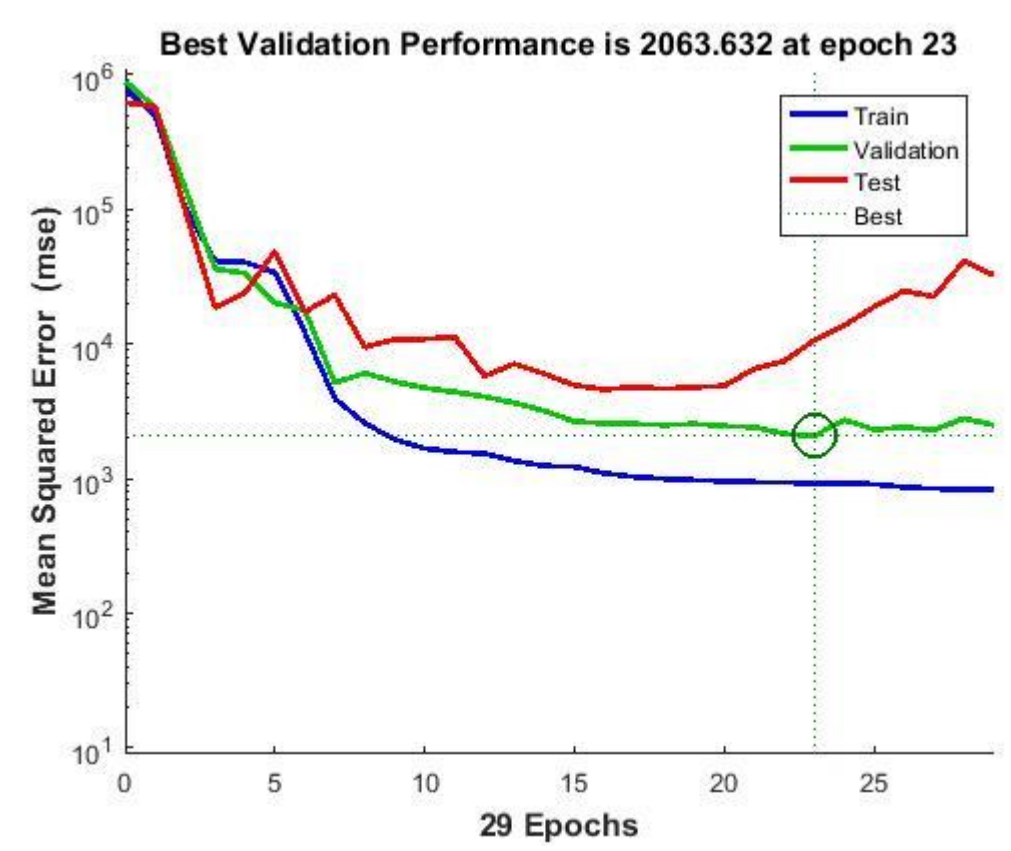

Figure 3. MSE for Trained ANN 

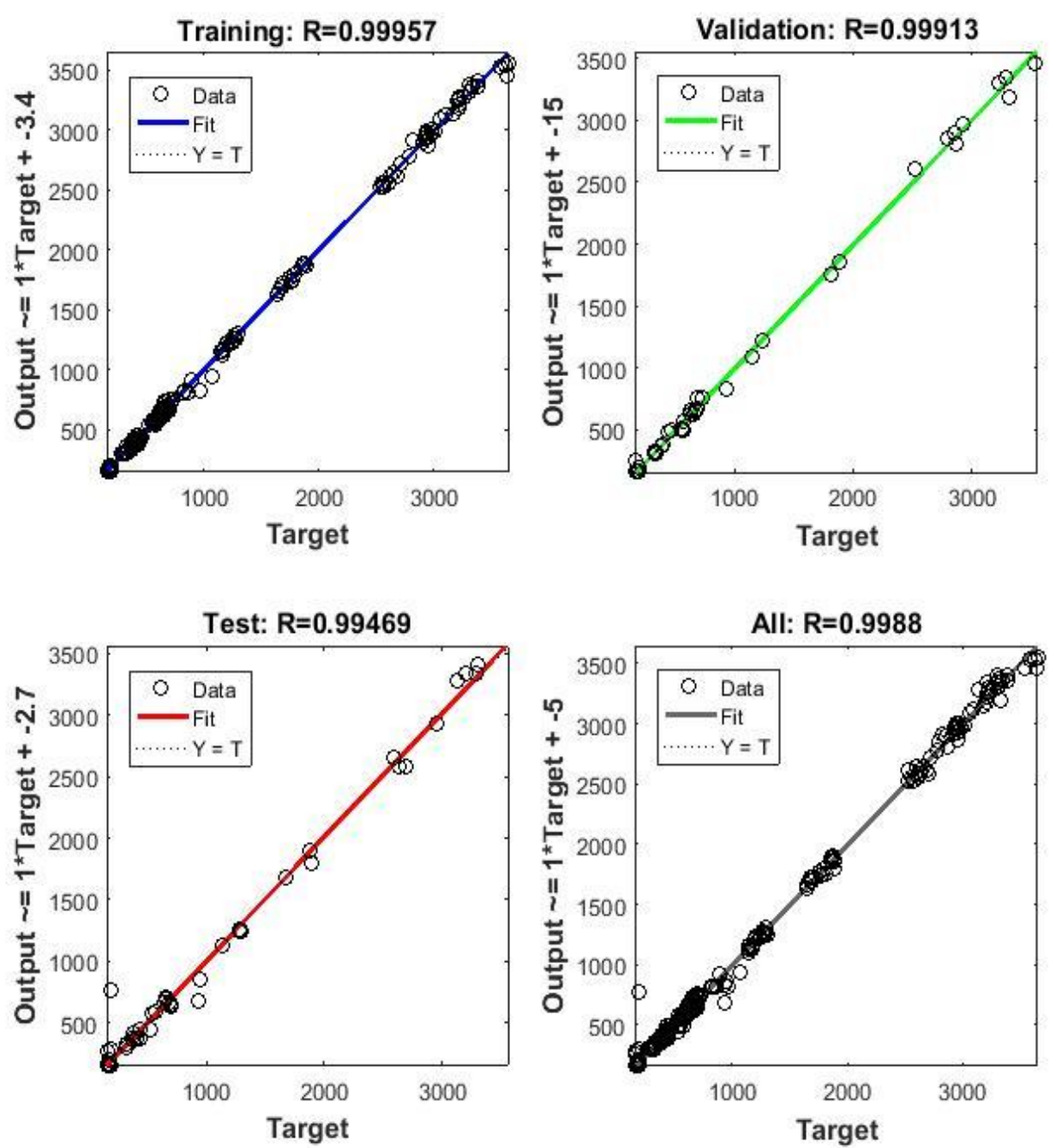

Figure 4. Regression Coefficient (R) Values for Trained ANN

\subsection{Stimulated Results for Voltage}

Trained ANN is used to stimulate the voltage output result for selected inputs and later these are matched with outputs obtained experimentally for same inputs.

Table 1. Stimulated Data obtained by ANN vs Experimental Data for Voltage

\begin{tabular}{|c|c|c|c|c|c|c|}
\hline Points & $\begin{array}{c}\text { LPG } \\
(\mathrm{lpm})\end{array}$ & $\begin{array}{l}\text { Max. Throat } \\
\text { opening (\%) }\end{array}$ & $\begin{array}{l}\text { Load } \\
(\%)\end{array}$ & $\begin{array}{l}\text { Voltage(V) } \\
\text { [experimental ] }\end{array}$ & $\begin{array}{l}\text { Voltage(V) } \\
\text { [stimulated ] }\end{array}$ & $\begin{array}{l}\text { Absolute } \\
\text { \% error }\end{array}$ \\
\hline 1 & 0.0 & 100 & 40 & 169 & 165.5502 & 2.04 \\
\hline 2 & 0.0 & 95 & 40 & 179 & 174.0002 & 2.79 \\
\hline 3 & 0.0 & 90 & 40 & 178 & 181.0001 & 1.68 \\
\hline 4 & 0.0 & 85 & 40 & 176 & 173.0237 & 1.70 \\
\hline 5 & 0.5 & 100 & 40 & 171 & 165.6632 & 3.12 \\
\hline 6 & 0.5 & 95 & 40 & 184 & 175.0001 & 4.89 \\
\hline 7 & 0.5 & 90 & 40 & 180 & 174.0005 & 3.33 \\
\hline
\end{tabular}




\begin{tabular}{|c|c|c|c|c|c|c|}
\hline 8 & 0.5 & 85 & 40 & 180 & 171.1594 & 4.91 \\
\hline 9 & 0.5 & 80 & 40 & 174 & 176.6214 & 1.50 \\
\hline 10 & 0.5 & 75 & 40 & 172 & 171.3530 & 0.38 \\
\hline 11 & 1.0 & 100 & 40 & 172 & 167.0295 & 2.90 \\
\hline 12 & 1.0 & 95 & 40 & 183 & 175.0001 & 4.37 \\
\hline 13 & 1.0 & 90 & 40 & 182 & 173.6874 & 4.56 \\
\hline 14 & 1.0 & 85 & 40 & 179 & 180.7568 & 0.97 \\
\hline 15 & 1.5 & 100 & 40 & 171 & 165.0000 & 3.50 \\
\hline 16 & 1.5 & 95 & 40 & 182 & 175.0000 & 3.84 \\
\hline 17 & 1.5 & 90 & 40 & 176 & 163.0001 & 7.38 \\
\hline 18 & 1.5 & 85 & 40 & 178 & 172.0066 & 3.37 \\
\hline 19 & 2.0 & 100 & 40 & 170 & 172.0193 & 1.18 \\
\hline \multicolumn{7}{|c|}{ Mean absolute percentage error (MAPE) } \\
\hline
\end{tabular}

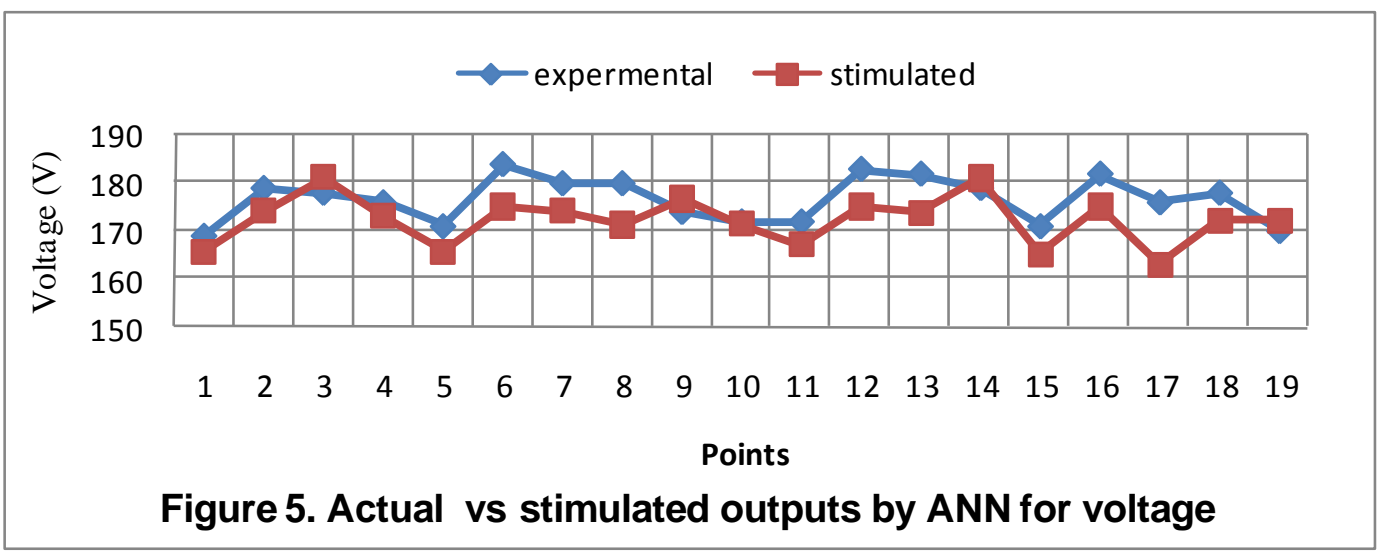

\subsection{Stimulated Results for Electrical Power Developed}

Trained ANN is used to stimulate the electrical power developed results for selected inputs and after that these are matched with outputs obtained experimentally for same inputs.

\section{Table 2. Stimulated Data vs Experimental Data for Electrical Power Developed}

\begin{tabular}{|c|c|c|c|c|c|c|}
\hline Points & $\begin{array}{l}\text { LPG } \\
(\mathrm{lpm})\end{array}$ & $\begin{array}{l}\text { Max. Throat } \\
\text { opening (\%) }\end{array}$ & $\begin{array}{l}\text { Load } \\
(\%)\end{array}$ & $\begin{array}{l}\text { Electrical power } \\
\text { developed } \\
\text { [experimental ] }\end{array}$ & $\begin{array}{l}\text { Electrical } \\
\text { power } \\
\text { developed } \\
(\mathrm{W}) \\
\text { [stimulated ] }\end{array}$ & $\begin{array}{l}\text { Absolute } \\
\% \text { error }\end{array}$ \\
\hline 1 & 0.0 & 100 & 40 & 2095 & 2159.117 & 3.06 \\
\hline 2 & 0.0 & 95 & 40 & 2243 & 2238.906 & 0.18 \\
\hline 3 & 0.0 & 90 & 40 & 2232 & 2178.774 & 2.42 \\
\hline 4 & 0.0 & 85 & 40 & 2195 & 2174.586 & 0.93 \\
\hline 5 & 0.5 & 100 & 40 & 2100 & 2090.973 & 0.53 \\
\hline 6 & 0.5 & 95 & 40 & 2396 & 2396.965 & 0.40 \\
\hline 7 & 0.5 & 90 & 40 & 2316 & 2372.518 & 2.44 \\
\hline 8 & 0.5 & 85 & 40 & 2365 & 2342.701 & 0.94 \\
\hline
\end{tabular}




\begin{tabular}{|c|c|c|c|c|c|c|}
\hline 9 & 0.5 & 80 & 40 & 2168 & 2144.939 & 1.06 \\
\hline 10 & 0.5 & 75 & 40 & 2153 & 2114.154 & 1.80 \\
\hline 11 & 1.0 & 100 & 40 & 2158 & 2165.615 & 0.35 \\
\hline 12 & 1.0 & 95 & 40 & 2387 & 2371.472 & 0.65 \\
\hline 13 & 1.0 & 90 & 40 & 2371 & 2354.298 & 0.70 \\
\hline 14 & 1.0 & 85 & 40 & 2275 & 2230.830 & 1.94 \\
\hline 15 & 1.5 & 100 & 40 & 2105 & 2100.497 & 0.22 \\
\hline 16 & 1.5 & 95 & 40 & 2354 & 2286.873 & 2.85 \\
\hline 17 & 1.5 & 90 & 40 & 2238 & 2136.302 & 4.55 \\
\hline 18 & 1.5 & 85 & 40 & 2247 & 2249.382 & 0.11 \\
\hline 19 & 2.0 & 100 & 40 & 2103 & 2144.726 & 1.98 \\
\hline \multicolumn{7}{|c|}{ Mean absolute percentage error (MAPE) } \\
\hline
\end{tabular}

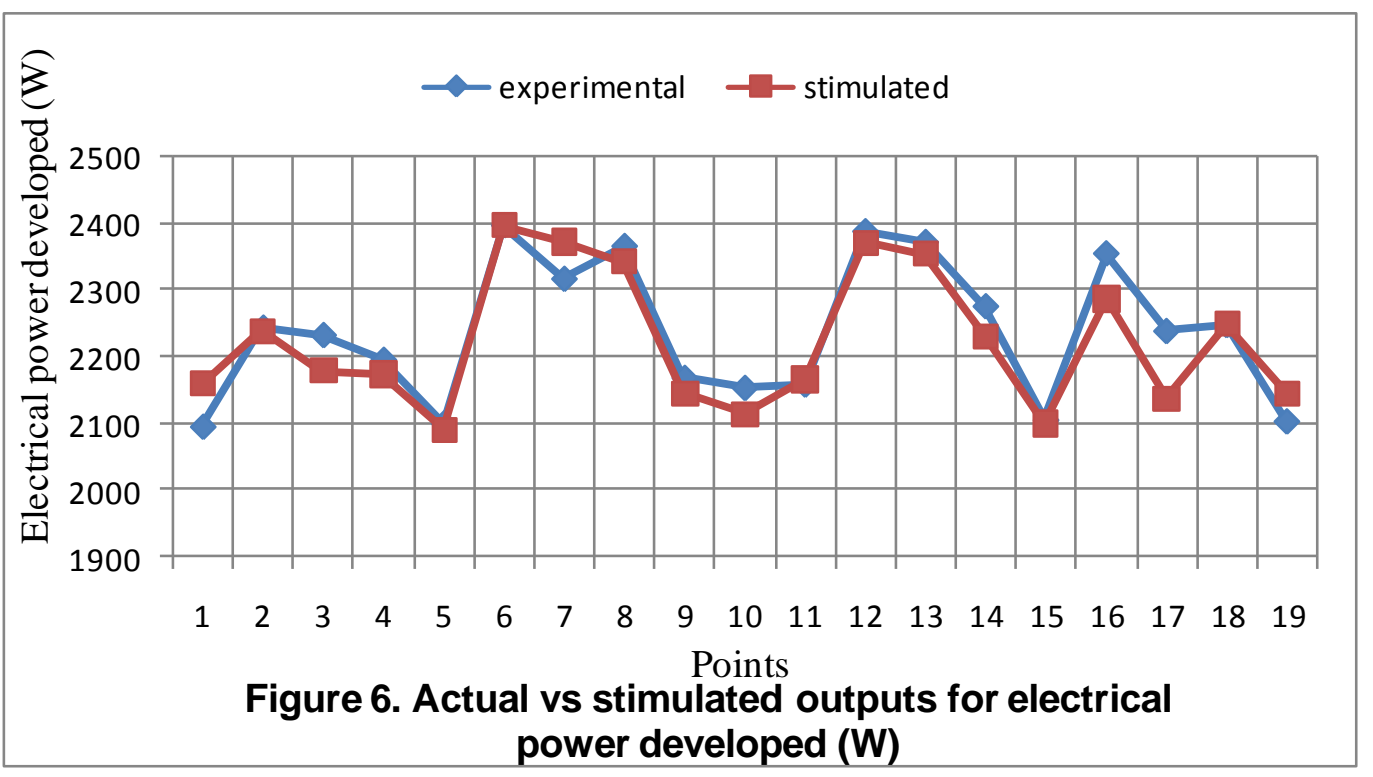

\subsection{Stimulated Results for Exhaust Gas Temperature}

Trained ANN is used to stimulate the EGT results for selected inputs and further these are matched with outputs obtained experimentally for same inputs.

Table 3. Stimulated Data obtained by ANN vs Experimental Data for EGT

\begin{tabular}{|c|c|c|c|c|c|c|}
\hline Points & $\begin{array}{l}\text { LPG } \\
(\mathrm{lpm})\end{array}$ & $\begin{array}{l}\text { Max. } \\
\text { Throat } \\
\text { opening }(\%)\end{array}$ & $\begin{array}{l}\text { Load } \\
(\%)\end{array}$ & $\begin{array}{l}\text { EGT }\left({ }^{\circ} \mathrm{C}\right) \\
{[\text { experimental }]}\end{array}$ & $\begin{array}{l}\text { EGT }\left({ }^{\circ} \mathrm{C}\right) \\
{[\text { stimulated }]}\end{array}$ & $\begin{array}{l}\text { Absolute \% } \\
\text { error }\end{array}$ \\
\hline 1 & 0.0 & 100 & 40 & 501 & 530.5608 & 5.90 \\
\hline 2 & 0.0 & 95 & 40 & 669 & 538.4311 & 19.50 \\
\hline 3 & 0.0 & 90 & 40 & 516 & 515.0708 & 0.18 \\
\hline 4 & 0.0 & 85 & 40 & 485 & 483.4926 & 0.31 \\
\hline 5 & 0.5 & 100 & 40 & 486 & 474.5334 & 2.35 \\
\hline 6 & 0.5 & 95 & 40 & 486 & 471.1137 & 3.06 \\
\hline 7 & 0.5 & 90 & 40 & 496 & 480.1315 & 3.20 \\
\hline 8 & 0.5 & 85 & 40 & 485 & 502.9362 & 3.70 \\
\hline 9 & 0.5 & 80 & 40 & 483 & 492.7972 & 2.03 \\
\hline 10 & 0.5 & 75 & 40 & 466 & 508.7154 & 9.17 \\
\hline 11 & 1.0 & 100 & 40 & 504 & 447.7429 & 11.10 \\
\hline
\end{tabular}




\begin{tabular}{|l|l|l|l|l|l|l|}
\hline 12 & 1.0 & 95 & 40 & 503 & 409.9995 & 18.40 \\
\hline 13 & 1.0 & 90 & 40 & 485 & 433.1602 & 10.70 \\
\hline 14 & 1.0 & 85 & 40 & 486 & 461.8561 & 4.96 \\
\hline 15 & 1.5 & 100 & 40 & 498 & 495.7720 & 0.60 \\
\hline 16 & 1.5 & 95 & 40 & 495 & 535.0160 & 8.10 \\
\hline 17 & 1.5 & 90 & 40 & 556 & 571.0846 & 2.70 \\
\hline 18 & 1.5 & 85 & 40 & 556 & 527.9628 & 5.10 \\
\hline 19 & 2.0 & 100 & 40 & 502 & 474.8358 & 5.40 \\
\hline \multicolumn{7}{|c|}{ Mean absolute percentage error (MAPE) } \\
\hline
\end{tabular}

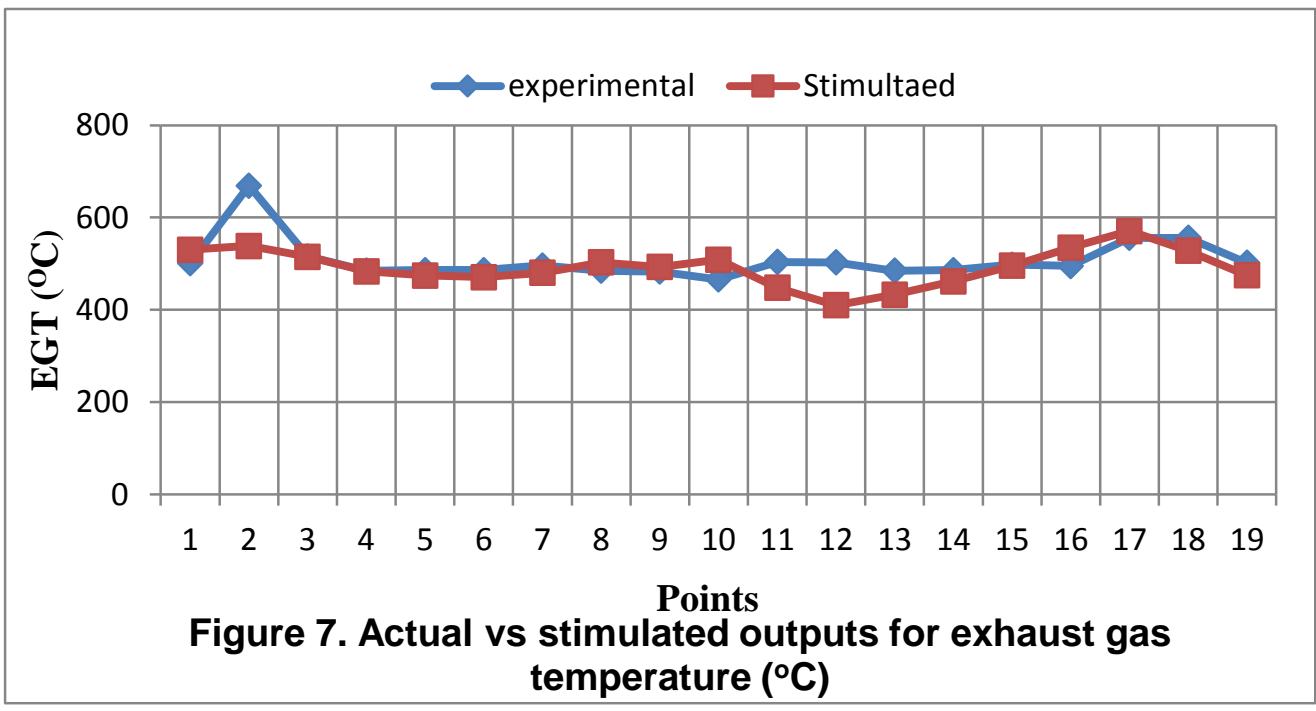

\subsection{Optimization using Hybrid Artificial Neural Network - Genetic Algorithm Method (ANN-GA)}

Process of optimization is done for the dual fuel engine for best output. Multi-objective optimization using genetic algorithm in the optimization tool box of MATLAB is used for optimization. Trained artificial neural network is used as fitness function for the optimization. Genetic algorithm used to minimize the function as a negative sign is put with the function so that overall function will be maximized. The optimization problem to be solved as follows:

Minimize: - Fitness function

Bounds: Flow rate of LPG [.5 1.5]

Maximum throat opening [85 100]

Load [40 70]

Bounds are deciding on the basis of experimental data.

Results of optimization

After optimization operation, input parameters for maximum output are as follows:

LPG flow rate in litre $/ \mathrm{min}=0.635$, Maximum throat opening $=86.333 \%, \mathrm{Load}=70 \%$

Table 4. Comparison between Outputs Parameters

\begin{tabular}{|l|c|c|c|}
\hline Output parameters & $\begin{array}{c}\text { Results by } \\
\text { optimization }\end{array}$ & Experimental results & $\%$ error \\
\hline Voltage $(\mathrm{V})$ & 155.0 & 163 & 5.16 \\
\hline Electrical power developed (W) & 3608.4 & 3772 & 4.53 \\
\hline EGT $\left({ }^{\circ} \mathrm{C}\right)$ & 595.41 & 638 & 7.15 \\
\hline Fuel consumption at these input parameters is $0.5 \mathrm{ml} / \mathrm{sec}$. \\
\hline
\end{tabular}


Readings can be verified with the snapshot of computer screen after optimization and digital multimeter after experimentally verification of results on setup.

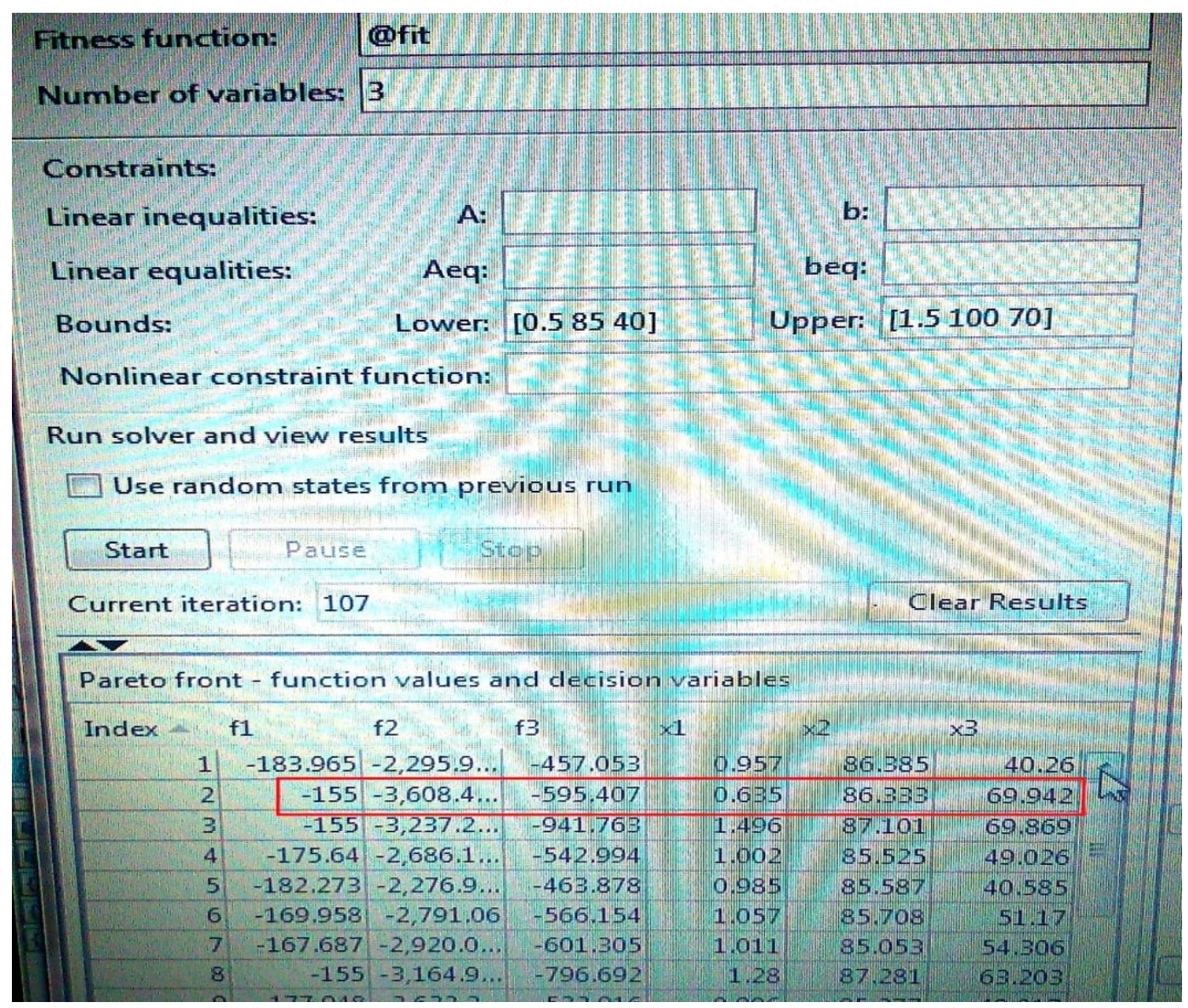

Figure 8. Snapshot of Computer Screen after Optimization

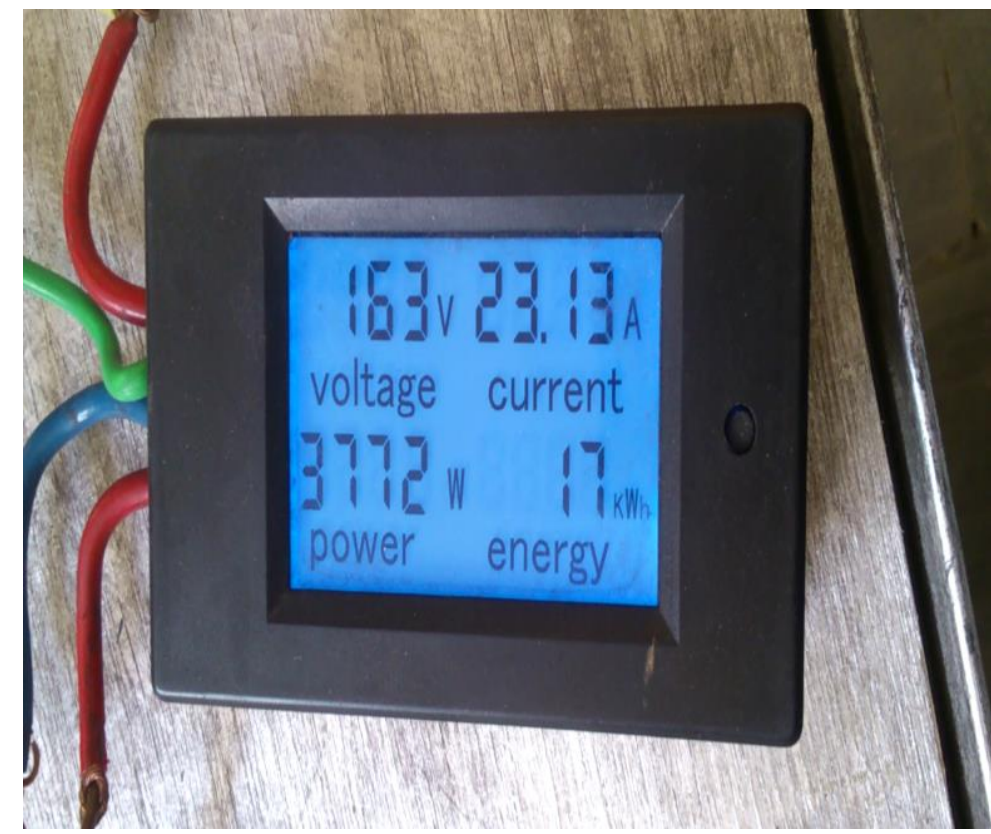

Figure 9. Snapshot of Digital Multi Metre after Experimental Verification of Readings 


\subsection{Economic Analysis}

In the economic analysis it assumed that if generator is run for 100 hours per year at the $70 \%$ load of maximum capacity of engine with having compressibility factor as 100 then the total running time of engine would be $1000 \mathrm{hr} / \mathrm{year}$ and for experimentally obtained data i.e. [1 lpm of LPG, $95 \%$ throat opening, $70 \%$ load, and fuel consumption is $0.6 \mathrm{ml} / \mathrm{s}$ ] the consumption of diesel and LPG would be around 2160 litre and $352.2 \mathrm{~kg}$ respectively. If the price of diesel is taken as Rs. 51 per litre and that of LPG price (commercial in India) as Rs. 1031 per $19 \mathrm{~kg}$ cylinder then the total cost incurred would be

$$
\text { Total cost }(\mathrm{A})=2160 * 51+352.2 * 54.26=129270.38 \mathrm{INR}
$$

Similarly, after the optimized results, for the obtained data i.e., [0.635 lpm of LPG, $86.33 \%$ throat opening, $70 \%$ load, fuel consumption is $0.5 \mathrm{ml} / \mathrm{s}$ ] the consumption of diesel and LPG would be around 1800 litre and $223.647 \mathrm{~kg}$ respectively. If the prices are same for Diesel and LPG, then the total cost incurred would be

$$
\text { Total cost }(B)=1800 * 51+223.647 * 54.26=102135.09 \mathrm{INR}
$$

The Net saving would be difference of A Minus B $=129270.38-102135.09=$ $27,135.32$ INR. The net saving on the basis of economic analysis is also shown in figure 10 below.

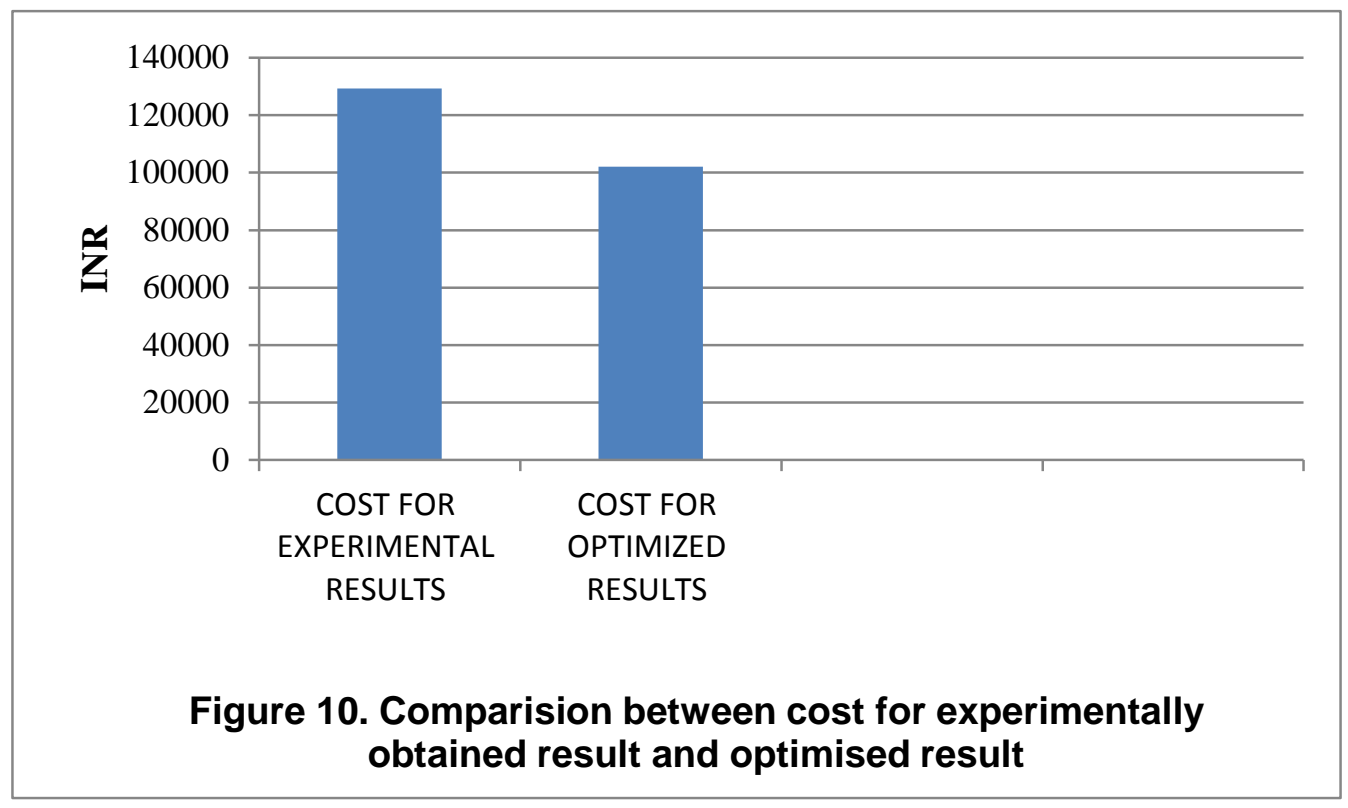

\section{Conclusion}

In this paper the conclusion in terms of effect of load on the engine, effect of fuel quantity and effect of varying amount of LPG is drawn as below:

\section{(i) Effect of load on the engine}

- Diesel-LPG dual fuel engine shows lower brake thermal efficiency and higher emission at the lower loads but for higher loads reverse is true.

- At Lower loads engine shows better brake thermal efficiency for full diesel operation and for higher loads with dual fuel mode.

- Engine running smoothly on higher loads. 
- Working with dual fuel mode shows higher noise levels in comparison with diesel mode as the load increased with increase in LPG supply rate while diesel flow rate kept constant.

- With the dual fuel mode of engine combustion period is high than only diesel values for low outputs because of ignition delay is higher. It's low at higher outputs than diesel values.

\section{(ii) Effect of fuel quantity}

- Increase in the diesel fuel quantity increases the available torque and thermal efficiency but the noise generated is higher than the operation only with diesel.

- High use of diesel quantity is effective in reducing harmful emission for all outputs.

- High diesel fuels quantity is used at lower loads for proper combustion of LPG. As the output power increased the diesel supply is decreased in order to reduce rapid combustion and knock.

\section{(iii) Effect of varying amount of LPG}

- Exhaust gas temperature increases and amount of exhaust emission decreases with increase LPG amount supplied.

- Amount of electrical power developed is increases and with the increases in LPG supplied.

\section{Acknowledgments}

The author is highly thankful to mechanical engineering department for extending help and support in fabricating the experimental set up. The contribution of B Tech final year student viz. Suyash Tiwari, Devanshu Kannaujia, Kuldeep Rao, Dileep Kumar and Swati Sankhwar of mechanical engineering is gratefully acknowledged under my supervision.

\section{References}

[1] B. Ashok, S. Denis Ashok and C. Ramesh Kumar, "LPG diesel dual fuel engine - A critical review", Alexandria engineering journal Elsevier.

[2] K. Mohan Kumar and D. Azad, "An experimental investigation of performance and emission of LPG as dual fuel in diesel engine generator", IJERA, ISSN: 2248-9622, vol. 4, no. 11 (Version 2), (2014) November, pp. 41-53

[3] A. Bilcan, O. Le Corre, M. Tazerout and A. Ramesh, "Characterization of the LPG- Diesel dual fuel combustion”, SAE Technical Paper, 2001-28-0036, (2001).

[4] R. S. Bharja, A. Chopraa and P. Roshaa, "Performance and emission characteristics of diesel and LPG dual fuel engine with exhaust gas recirculation", Department of Mechanical Engineering, National Institute of Technology, Jalandhar-144011, India.

[5] A. Rai, N. Sateesh Kumar, Srinivas Pai P. and B. R. Srinivas Rao, "Fuzzy logic based prediction of performance and emission parameters of a LPG-diesel dual fuel engine”, vol. 38, (2012).

\section{Authors}

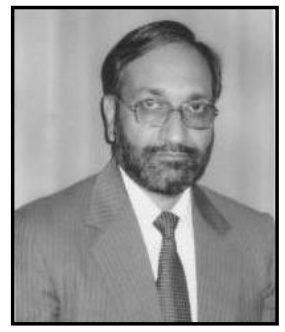

J P Yadav is Professor \& Head, Mechanical Engineering department and Dean of College of Agricultural Engineering \& Technology of Chandra Shekhar Azad University of Agriculture and Technology, campus at Etawah (U.P.) - India. Dr. Yadav has large number of research papers in journals and conference proceedings to his credit. He is recipient of $\mathrm{Dr} \mathrm{CV}$ Paul Distinguished Agricultural Scientist award by UPAAS and Best Agricultural Scientist award by UP Government. 


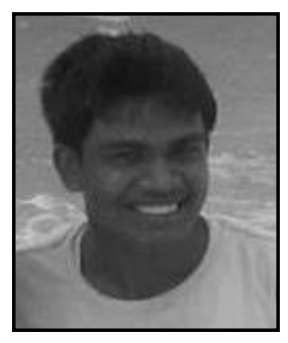

Amit Kumar is B Tech graduate and alumnus of Chandra Shekhar Azad University of Agriculture and Technology, campus at Etawah (U.P.) - India. His areas of interest include thermal engineering, internal combustion engine, and alternative fuels.

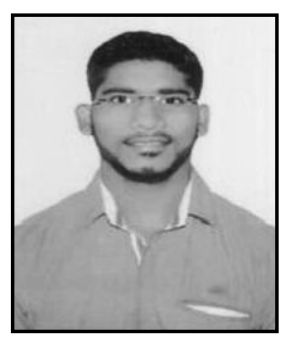

Ravi Kant is B Tech graduate and alumnus of Chandra Shekhar Azad University of Agriculture and Technology, campus at Etawah (U.P.) - India. His areas of interest include thermal engineering, internal combustion engine, and alternative fuels. 